\title{
Lessons from obesity prevention for the prevention of mental disorders: the primordial prevention approach
}

\author{
Joshua Hayward $^{1 *}$, Felice N Jacka ${ }^{2}$, Elizabeth Waters $^{3}$ and Steven Allender ${ }^{1}$
}

\begin{abstract}
Background: Emerging evidence supports a relationship between risk factors for obesity and the genesis of the common mental disorders, depression and anxiety. This suggests common mental disorders should be considered as a form of non-communicable disease, preventable through the modification of lifestyle behaviours, particularly diet and physical activity.

Discussion: Obesity prevention research since the 1970's represents a considerable body of knowledge regarding strategies to modify diet and physical activity and so there may be clear lessons from obesity prevention that apply to the prevention of mental disorders. For obesity, as for common mental disorders, adolescence represents a key period of vulnerability. In this paper we briefly discuss relationships between modifiable lifestyle risk factors and mental health, lifestyle risk factor interventions in obesity prevention research, the current state of mental health prevention, and the implications of current applications of systems thinking in obesity prevention research for lifestyle interventions.
\end{abstract}

Summary: We propose a potential focus for future mental health promotion interventions and emphasise the importance of lessons available from other lifestyle modification intervention programmes.

Keywords: Obesity prevention, Common mental disorders, Prevention, Intervention design, Complex intervention, Systems

\section{Background}

The common mental disorders (CMDs) depression and anxiety, are now presenting as major global public health problems. Recent burden of disease studies have attributed as much as $7.4 \%$ of global disability adjusted life-years to mental and behavioural disorders, with $2.5 \%$ attributable to major depressive disorder (MDD) alone [1]. Although a matter of some contention, the available data suggest an increase in the prevalence of CMDs [2], particularly in young people $[3,4]$. Importantly, recent evidence from large-scale prospective cohort studies suggest that physical inactivity and unhealthy diet, are related to the genesis of the CMDs [5-8].

The World Health Organization (WHO) framework for the causes of noncommunicable disease (NCD) proposes that physical inactivity and unhealthy diet are among the key modifiable lifestyle risk behaviours that underlie most NCD's [9]. Recently, there has been an increasing focus on the potential for, and importance of, taking a preventive approach to mental disorders [10] and authors have suggested that programs which also view CMDs as lifestyleinformed NCDs, with population-level lifestyle modification components, may be useful in the prevention of CMDs [11]. In order to elucidate lessons for future CMD prevention, this commentary briefly discusses the relationships between modifiable lifestyle risk factors and CMDs, characteristics of successful preventive approaches to obesity that are of relevance to the prevention of mental disorders, and the role of systems thinking in strengthening lifestyle risk factor interventions.

\footnotetext{
* Correspondence: jnh@deakin.edu.au

${ }^{1}$ World Health Organization Collaborating Centre for Obesity Prevention,

Deakin University, 1 Gheringhap St, Geelong, Victoria 3220, Australia

Full list of author information is available at the end of the article
} 


\section{Discussion}

\section{Modifiable lifestyle risk factors and common mental disorders}

Since 2009 emerging literature has demonstrated the importance of diet quality to the CMDs [11,12]. For example, the most recent meta-analysis in this field has reported a $30 \%$ reduction in the risk for depression in those with high adherence to a Mediterranean dietary pattern $(\mathrm{RR}=0.68,95 \% \mathrm{CI}=0.54-0.86)$, [13] while a 'healthy' diet pattern is also associated with a reduced likelihood of depression (OR: 0.84; 95\% CI: 0.76, 0.92) [14]. Although dietary data to date have been largely observational in nature, a recent large-scale European intervention supports the contention that targeting dietary improvement can prevent some cases of CMDs [15]. Knowledge regarding the contribution of physical inactivity to depression risk has also increased; a recent systematic review with 30 included studies concluded that physical activity was negatively associated with a risk of subsequent depression [16]. Individual studies show that as little as 10-29 minutes of daily physical activity may be adequate to reduce relative risk of clinical depression in women ( $R R=0.9 ; 95 \%$ CI: $0.84-0.96)$ [7]. A recent review by Sarris et al. [17] examined in detail the evidence for the use of lifestyle modification as a clinical treatment strategy for depression. The report concluded that physical activity, diet, and a range of other lifestyle factors (including mindfulness-based meditation, sleep regulation, social interaction and others) show clear relevance not only for the clinical management of depression, but also for potential population-level mental health promotion. These findings support the contention that diet and physical activity are shared risk factors for many physical and mental disorders and suggest that targeting lifestyle behaviours may be an effective strategy in the prevention of mental disorders.

\section{Modifiable lifestyle risk factors in obesity prevention} Obesity prevention research now has a 25-plus year history of targeted lifestyle behaviour interventions, beginning in the 1980's [18]. The "core" of the obesity problem has long been conceptualised as the result of prolonged energy imbalance, driven by the same lifestyle risk factors discussed in relation to CMD above (physical inactivity and unhealthy nutrition). Recently, obesity prevention research has begun to understand the complex nature of the relationships and interdependencies between physical inactivity and unhealthy nutrition, concluding that these behaviours can be resistant to change if targeted in isolation [19]. Recent work in the obesity prevention field therefore provides valuable insights into how CMD prevention may similarly target these lifestyle risk factors and in this paper we examine this in relation to a particularly high risk time of development; that of adolescence.
Waters et al. [20] have reviewed the childhood obesity prevention intervention literature focusing on studies including controlled designs since 1997. The most recent update included 55 obesity interventions that took place between 1993 and 2010. The review located 8 interventions which specifically targeted $13-18$ year olds, and reported that all programs targeted physical activity outcomes, and that six of the eight targeted a range of nutrition-related targets. Several studies within this subgroup reported significant increases in the measured lifestyle outcomes, with three studies reporting significant dietary improvements [21-23] and five studies reporting increased indicators of physical activity [21,24-27], however in some interventions these effects were not sustained over time [23].

Some key limitations were noted within these studies. The majority of the evidence reviewed was derived from interventions with short-term funding, based on strategies that optimally require long-term funding support for effect longevity (school-based programs requiring direct funding from investigators, etc.). Accordingly, the overall effectiveness of these interventions was modest $(-0.15$ (95\% CI $-0.21,-0.09)$ BMI-z points, [20]). Leaders in obesity prevention suggest these modest results reflect a failure to anticipate the complexity of drivers of population lifestyle behaviours, the potential plasticity of risk factors when addressed in isolation, and post-intervention effect dropoff. The review noted that the most promise seems to lie with programs which comprehensively target multiple risk factors, coupled with psychosocial support and environmental change [20].

A second theme emerging from obesity prevention is the Community Capacity Building (CCB) approach, an innovative method of developing sustainable skills, resources, and organisational structure, around a shared health promotion goal, within the community itself [28]. This approach addresses complex, interrelated risk factors by using broad community engagement to tailor intervention approaches to the specific set of social and environmental circumstances that exist within that community.

There have been recent interventions drawing on this framework, including the "It's Your Move" (IYM) project in the Barwon South-West region of Victoria, Australia [29]. The intervention focussed on community engagement to foster flexible intervention strategies across multiple community sectors and organisational levels. The program was deemed to have successfully reduced overweight and obesity in adolescents, and although some nutritional behaviours remained unchanged, the program did observe increases in active transport in the intervention group [29]. Recent analysis suggested that schools which had large increases in readiness for change throughout the intervention demonstrated significant BMI decreases at followup [30]. 


\section{Complex interventions in CMD prevention}

The importance of taking complex, multi-component approaches to prevention is also increasingly recognised in CMD research. A review by Weare and Nind highlighted several characteristics of successful school-based mental health promotion programmes, finding that universal programmes, which are embedded within the school curriculum and culture, as well as build teacher capacity and knowledge, and involve the wider community, have demonstrated a wide range of benefits to children's mental health, social, and educational outcomes [31].

An Australian example of this approach was the Gatehouse Project, a group randomised trial employed to address risky health behaviours and improve emotional well-being in secondary school aged children [32]. This approach embedded strategies within the school curriculum to improve students' emotional management and interpersonal communication skills, while promoting inclusiveness within the classroom. This intervention was successful in reducing risky health behaviours, including substance use and antisocial behaviours. Although this intervention was not successful in directly reducing students' symptoms of emotional problems [33], the complex strategies employed to achieve improvements in risky health behaviours in this study have been adopted widely around the globe in both high and low income settings. Existing observational data on Australian adolescents supports the contention that using such multi-component, integrated strategies to address lifestyle-related behaviours may result in positive benefits for mental health outcomes in this age group [5,34].

\section{The systems perspective: new frameworks for working at scale}

As understanding of the complexity of lifestyle risk factor interventions has increased, prevention science is observing a gradual shift from individual risk-factor approaches, through multiple risk-factor approaches, community capacity and multi-level approaches, to a recent emphasis on systems thinking as a framework for addressing complexity.

The systems perspective acknowledges not only the existence of the multiple causal factors which drive complex health problems, but highlights their interrelated and "dynamic" associations as an important consideration for any intervention program [35]. Systems thinking has gained some traction is obesity research, being highlighted as the underpinning theory behind population level intervention programmes in Victoria, Australia [36]. The lack of significant inroads into preventing either obesity or CMDs in adolescence supports the need for an alternate approach more able to deal with these complex drivers.

\section{Summary}

A systems perspective, which posits that complex problems lack simple or obvious solutions, shows that prevention efforts must be based in a deeper understanding of the dynamic complexity of modifiable lifestyle risk-factors [19,35]. Current complex, multi-component approaches to CMD prevention have had mixed success but show promise for further development. To capitalise on lessons learned from the obesity prevention sphere, significant collaboration with existing complex population-level lifestyle interventions appears critical.

\section{Abbreviations}

BMI: Body mass index; CCB: Community capacity building; CMD: Common mental disorder; CVD: Cardio vascular disease; DALY: Disability adjusted life year; IYM: It's your move; MDD: Major depressive disorder; NCD: Non communicable disease; NHANES: National Health and Nutrition Examination Survey; WHO: World Health Organization.

\section{Competing interests}

The authors declare that they have no competing interests.

\section{Authors' contributions}

$J \mathrm{H}$, conceived the paper, composed the initial drafts, oversaw drafting and editing of contributions from other authors and managed the MS to submission. SA, FJ \& EW contributed to subsequent drafts and provided expert knowledge in the fields of NCD, CMD and KT \& E respectively. All authors read and approved the final manuscript.

\section{Authors' information}

$\mathrm{JH}$ holds a Bachelor of Psychology (hons) and is a PhD candidate at the World Health Organization Collaborating Centre for Obesity Prevention at Deakin University, Australia. FJ is an associate professor in the Deakin University School of Medicine based at Barwon Health, Australia, and is an honorary Research Fellow at the University of Melbourne. EW is a professor at the University of Melbourne and chairs the Jack Brockhoff Child Health and Wellbeing program at the University of Melbourne's School of Population and Global Health. SA is a professor in population health and is the co-director of the World Health Organization Collaborating Centre for Obesity Prevention at Deakin University, Australia.

\section{Acknowledgements}

SA is supported by funding from an Australian National Health and Medical Research Council/Australian National Heart Foundation Career Development Fellowship (APP1045836). SA is a researcher within a NHMRC Centre for Research Excellence in Obesity Policy and Food Systems (APP1041020). SA is supported by US National Institutes of Health grant titled Systems Science to Guide Whole-of-Community Childhood Obesity Interventions (1R01HL115485-01A1).

\section{Author details}

'World Health Organization Collaborating Centre for Obesity Prevention, Deakin University, 1 Gheringhap St, Geelong, Victoria 3220, Australia. ${ }^{2}$ IMPACT Strategic Research Centre, Deakin University, Barwon Health, Ryrie St, Geelong, Victoria 3220, Australia. ${ }^{3}$ Jack Brockhoff Child Health and Wellbeing Program, Melbourne School of Population and Global Health, The University of Melbourne, 5/207 Bouverie St, Carlton, Victoria 3053, Australia.

Received: 3 April 2014 Accepted: 29 August 2014

Published online: 10 September 2014

\section{References}

1. Murray CJL, Vos T, Lozano R, Naghavi M, Flaxman AD, Michaud C, Ezzati M, Shibuya K, Salomon JA, Abdalla S, Aboyans V, Abraham J, Ackerman I, Aggarwal R, Ahn SY, Ali MK, Alvarado M, Anderson HR, Anderson LM, Andrews KG, Atkinson C, Baddour LM, Bahalim AN, Barker-Collo S, Barrero LH, Bartels DH, Basáñez MG, Baxter A, Bell ML, Benjamin EJ, et al: Disability-adjusted life years (DALYs) for 291 diseases and injuries in 21 
regions, 1990-2010: a systematic analysis for the Global Burden of Disease Study 2010. Lancet 2012, 380(9859):2197-2223.

2. Fu TS, Lee CS, Gunnell D, Lee WC, Cheng AT: Changing trends in the prevalence of common mental disorders in Taiwan: a 20-year repeated cross-sectional survey. Lancet 2013, 381(9862):235-241.

3. Collishaw S, Maughan B, Goodman R, Pickles A: Time trends in adolescent mental health. J Child Psychol Psychiat 2004, 45(8):1350-1362.

4. Twenge JM, Gentile B, DeWall CN, Ma D, Lacefield K, Schurtz DR: Birth cohort increases in psychopathology among young Americans, 1938-2007: A cross-temporal meta-analysis of the MMPI. Clin Psychol Rev 2010, 30(2):145-154

5. Jacka FN, Kremer PJ, Berk M, de Silva-Sanigorski AM, Moodie M, Leslie ER, Pasco JA, Swinburn BA: A prospective study of diet quality and mental health in adolescents. PLoS One 2011, 6(9):e24805.

6. Akbaraly TN, Brunner EJ, Ferrie JE, Marmot MG, Kivimaki M, Singh-Manoux A: Dietary pattern and depressive symptoms in middle age. Br J Psychiatry 2009, 195(5):408-413.

7. Lucas M, Mekary R, Pan A, Mirzaei F, O'Reilly É, Willett WC, Koenen K, Okereke OI, Ascherio A: Relation between clinical depression risk and physical activity and time spent watching television in older women: a 10-year prospective follow-up study. Am J Epidemiol 2011, 174(9):1017-1027.

8. Sánchez-Villegas A, Delgado-Rodríguez M, Alonso A, Schlatter J, Lahortiga F, Serra Majem L, Martínez-González MA: Association of the mediterranean dietary pattern with the incidence of depression: the seguimiento universidad de navarra/university of navarra follow-up (sun) cohort. Arch Gen Psychiatry 2009, 66(10):1090-1098.

9. World Health Organization: Global status report on noncommunicable diseases. In WHO Library Cataloguing-in-Publication Data. Edited by Alwan A. Geneva: WHO Press; 2010

10. Jacka FN, Reavley NJ, Jorm AF, Toumbourou JW, Lewis AJ, Berk M: Prevention of common mental disorders: what can we learn from those who have gone before and where do we go next? Aust NZ J Psychiat 2013, 47(10):920-929.

11. Jacka FN, Mykletun A, Berk M: Moving towards a population health approach to the primary prevention of common mental disorders. BMC Med 2012, 10(1):149-154.

12. Jacka FN, Ystrom E, Brantsaeter AL, Karevold E, Roth C, Haugen M, Meltzer HM, Schjolberg S, Berk M: Maternal and early postnatal nutrition and mental health of offspring by age 5 years: a prospective cohort study. J Am Acad Child Adolesc Psychiatry 2013, 52(10):1038-1047.

13. Psaltopoulou T, Sergentanis TN, Panagiotakos DB, Sergentanis IN, Kosti R, Scarmeas N: Mediterranean diet, stroke, cognitive impairment, and depression: a meta-analysis. Ann Neurol 2013, 74(4):580-591.

14. Lai JS, Hiles S, Bisquera A, Hure AJ, McEvoy M, Attia J: A systematic review and meta-analysis of dietary patterns and depression in community-dwelling adults. Am J Clin Nutr 2014, 99(1):181-197.

15. Sánchez-Villegas A, Martínez-González M, Estruch R, Salas-Salvadó J, Corella D, Covas M, Arós F, Romaguera D, Gómez-Gracia E, Lapetra J, Pintó X, Martínez JA, Lamuela-Raventós RM, Ros E, Gea A, Wärnberg J, Serra-Majem L: Mediterranean dietary pattern and depression: the PREDIMED randomized trial. BMC Med 2013, 11(1):208.

16. Mammen G, Faulkner G: Physical activity and the prevention of depression: a systematic review of prospective studies. Am J Prev Med 2013, 45(5):649-657.

17. Sarris J, O'Neil A, Coulson C, Schweitzer I, Berk M: Lifestyle medicine for depression. BMC Psychiatry 2014, 14(1):107.

18. Glenny AM, O'Meara S, Melville A, Sheldon TA, Wilson C: The treatment and prevention of obesity: a systematic review of the literature. Int J Obes (Lond) 1997, 21(9):715-737.

19. Finegood DT, Merth TDN, Rutter H: Implications of the foresight obesity system map for solutions to childhood obesity. Obesity (Silver Spring, Md) 2010, 18(Suppl 1):S13-S16.

20. Waters E, de Silva-Sanigorski A, Hall BJ, Brown T, Campbell KJ, Gao Y, Armstrong R, Prosser L, Summerbell CD: Interventions for preventing obesity in children. Cochrane Database Syst Rev 2011, (12):CD001871.

21. Haerens L, Deforche B, Maes L, Cardon G, Stevens V, De Bourdeaudhuij I: Evaluation of a 2-year physical activity and healthy eating intervention in middle school children. Health Educ Res 2006, 21(6):911-921.

22. Ebbeling CB, Feldman HA, Osganian SK, Chomitz VR, Ellenbogen SJ, Ludwig DS: Effects of decreasing sugar-sweetened beverage consumption on body weight in adolescents: a randomized, controlled pilot study. Pediatrics 2006, 117(3):673-680.

23. Singh AS, Paw MJ, Brug J, van Mechelen W: Short-term effects of school-based weight gain prevention among adolescents. Arch Pediatr Adolesc Med 2007, 161(6):565-571.

24. Pate RR, Ward DS, Saunders RP, Felton G, Dishman RK, Dowda M: Promotion of physical activity among high-school girls: a randomized controlled trial. Am J Public Health 2005, 95(9):1582-1587.

25. Peralta LR, Jones RA, Okely AD: Promoting healthy lifestyles among adolescent boys: the Fitness Improvement and Lifestyle Awareness Program RCT. Prev Med 2009, 48(6):537-542.

26. Patrick K, Calfas KJ, Norman GJ, Zabinski MF, Sallis JF, Rupp J, Covin J, Cella J: Randomized controlled trial of a primary care and home-based intervention for physical activity and nutrition behaviors: PACE + for adolescents. Arch Pediatr Adolesc Med 2006, 160(2):128-136.

27. Webber LS, Catellier DJ, Lytle LA, Murray DM, Pratt CA, Young DR, Elder JP, Lohman TG, Stevens J, Jobe JB, Pate RR, TAAG Collaborative Research Group-: Promoting physical activity in middle school girls trial of activity for adolescent girls. Am J Prev Med 2008, 34(3):173-184.

28. Waters $\mathrm{E}(\mathrm{Ed})$ : Preventing childhood obesity: evidence, policy and practice. Chichester, West Sussex; Hoboken, NJ: Wiley-Blackwell: BMJ Books; 2010.

29. Millar L, Kremer P, de Silva-Sanigorski A, McCabe MP, Mavoa H, Moodie M, Utter J, Bell C, Malakellis M, Mathews L, Roberts G, Robertson N, Swinburn BA: Reduction in overweight and obesity from a 3-year community-based intervention in Australia: the 'It's Your Move!' project. Obes Rev 2011, 12:20-28.

30. Millar L, Robertson N, Allender S, Nichols M, Bennett C, Swinburn B: Increasing community capacity and decreasing prevalence of overweight and obesity in a community based intervention among Australian adolescents. Prev Med 2013, 56(6):379-384.

31. Weare K, Nind M: Mental health promotion and problem prevention in schools: what does the evidence say? Health Promot Int 2011, 26(Supplement 1):i29-i69.

32. Patton GC, Glover S, Bond L, Butler H, Godfrey C, Pietro GD, Bowes G: The Gatehouse Project: a systematic approach to mental health promotion in secondary schools. Aust NZ J Psychiat 2000, 34(4):586-593.

33. Bond L, Patton G, Glover S, Carlin JB, Butler H, Thomas L, Bowes G: The Gatehouse Project: can a multilevel school intervention affect emotional wellbeing and health risk behaviours? J Epidemiol Commun H 2004 58(12):997-1003.

34. Jacka FN, Kremer PJ, Leslie ER, Berk M, Patton GC, Toumbourou JW, Williams JW: Associations between diet quality and depressed mood in adolescents: results from the Australian Healthy Neighbourhoods Study. Aust NZ J Psychiat 2010, 44(5):435-442.

35. Craig P, Dieppe P, Macintyre S, Michie S, Nazareth I, Petticrew M: Developing and evaluating complex interventions: the new Medical Research Council guidance. Int J Nurs Stud 2013, 50(5):587-592.

36. Victorian State Government: Strengthening Victoria's prevention system. Melbourne: Department of Health; 2014

\section{doi:10.1186/s12888-014-0254-3}

Cite this article as: Hayward et al:: Lessons from obesity prevention for the prevention of mental disorders: the primordial prevention approach. BMC Psychiatry 2014 14:254

\section{Submit your next manuscript to BioMed Central and take full advantage of:}

- Convenient online submission

- Thorough peer review

- No space constraints or color figure charges

- Immediate publication on acceptance

- Inclusion in PubMed, CAS, Scopus and Google Scholar

- Research which is freely available for redistribution 